\title{
Angiotensin-Induced Growth Related Metabolism Is Activated in Cultured Smooth Muscle Cells From Spontaneously Hypertensive Rats and Wistar-Kyoto Rats
}

\author{
Timothy Scott-Burden, Thérèse J. Resink, Alfred W. A. Hahn, and Fritz R. Bühler
}

Smooth muscle cells from spontaneously hypertensive rats (SHR) proliferate in culture faster than those isolated from sex- and age-matched WistarKyoto (WKY) animals. There was no difference in the kinetics of $\mathbf{S 6}$ kinase activation in the two cultures, but later metabolic events associated with proliferation were stimulated earlier in SHR cells than in WKY, eg, activation of ornithine decarboxylase. Both cell types elaborated an extensive extracellular matrix in culture composed of a different blend of connective tissue macromolecules. Matrix material from SHR cells was more stimulatory to growth of WKY cultures than their own matrices. Angiotensin stimulated the growth and synthesis of extra-cellular matrix material in SHR more than in WKY derived vascular smooth muscle cell cultures. Am J Hypertens 1991;4:183-188

KEY WORDS: Angiotensin, vascular smooth muscle growth metabolism.
$\mathrm{T}$ he well established concepts embodied in the "response to injury theory," as proposed by Ross and Glomset, ${ }^{1}$ has provided a model for the study of the many factors and their interaction responsible for the pathogenesis of vascular disease under situations where frank denudation of the endothelium has taken place. ${ }^{2-4}$ There is now evidence to suggest that both hypertrophy and hyperplasia can occur in the absence of any apparent damage to the endothelial layer. ${ }^{5-7}$ For these processes to take place we need to invoke the influences of compounds that are normally present in the intact blood vessel wall.

Candidates for the processes mentioned $a b c^{-}$in-

From the Department of Research, University Hospital, Basel, Switzerland.

This study was supported by the Swiss National Fund Number 3.817.087.

Address correspondence and reprint requests to Professor F. R Bühler, Department of Research, University Hospital, Ch-4031 Basel, Switzerland. clude compounds that have been characterized as growth factors, as well as a number of molecules normally associated with the structural components of the vessel wall (see Figure 1). Among these extracellular matrix compounds, thrombospondin (TS) has certain attributes which strongly suggest that it could play an important role in a variety of processes that eventually lead to the development of vascular disease. ${ }^{8-10}$ The vasoactive peptide hormones are another group of molecules that have received attention with regard to their pathogenic potential. In this respect angiotensin II (Ang II) has been suggested to induce irreversible vascular changes. ${ }^{11,12}$ Clearly, the latter is a candidate eminently suited to playing a role in the chronic progressive induction of the vascular structural changes that are part and parcel of essential hypertension (EHT), since more than two thirds of patients with EHT exhibit elevated plasma renin/Ang II levels relative to the height of their blood pressure. ${ }^{13,14}$ Recent reports have shown that indeed Ang II is capable of stimulating a number of metabolic events that may lead to smooth muscle proliferative 


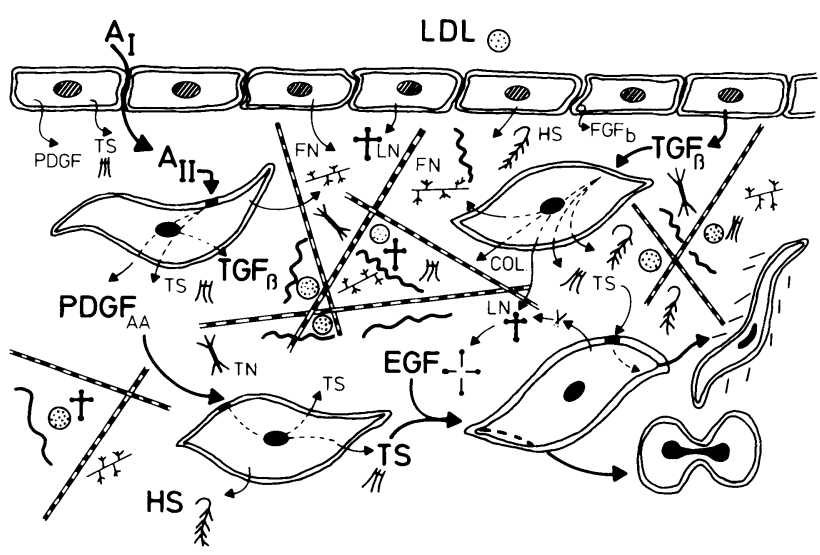

FIGURE 1. Schematic representation of vessel wall and some components thereof which may contribute to the pathogenesis of vascular disease. Matrix molecules: fibronectin (FN); laminin (LN); thrombospondin (TS); tenascin (TN); collagen (COL); heparan sulfate/heparin and elastin (HS). Growth Factors/Stimulators: epidermal growth factor (EGF); basic fibroblast growth factor $\left(F G F_{b}\right)$; platelet derived growth factor (PDGF); transforming growth factor $\beta\left(T G F_{\beta}\right)$; angiotensin (AII) and low density lipoprotein (LDL). Furthermore, within the matrix compounds such as $L D L$ and basic fibroblast growth factor can be bound. In the course of the normal turnover of matrix molecules which accompanies the dynamic process of tissue remodelling, peptide fragments having EGF domains can be generated and some of the stimulatory properties of this growth factor may become manifest. The compounds known to possess such EGF domains include LN, TS, and TN, a recently discovered matrix glycoprotein also found in vascular tissue. ${ }^{39}$ Both endothelial and smooth muscle cells are capable of secreting a number of growth factors without or with agonist stimulation, eg, Ang II. These events may lead to either hypertrophy or hyperplasia as well as the promotion of migration into the intimal space (see Discussion).

behavior. ${ }^{11,12,15}$ The induction of $\mathrm{c}-\mathrm{fos}, \mathrm{c}-\mathrm{myc}$, and PDGF A chain gene expression in cultures of rat smooth muscle cells by Ang II, ${ }^{11,12}$ as well as its ability to stimulate protein synthesis, ${ }^{15,16}$ strongly suggest that chronic exposure of vascular smooth muscle to this vasoactive peptide may have pathologic consequences.

We report here on our investigations with Ang II using cultured smooth muscle cells from spontaneously hypertensive rats (SHR) and their normotensive WistarKyoto (WKY) litter mates. We also report here on the use of plasma-derived serum (PDS) in conjunction with Ang II for the prolonged propagation of cultured rat smooth muscle cells. Our rationale for the use of PDS is that under normal physiologic conditions medial smooth muscle cells would not come into contact with serum from whole blood, but are rather "bathed by a filtrate of plasma," 17 essentially similar to the nonmitogenic preparations we have used in some of these studies.

\section{MATERIALS AND METHODS}

All materials and media for tissue culture were obtained from sources already described. ${ }^{18}$ The radioisotopes used in the studies described herein were purchased from Amersham Radiochemical, Amersham, Buckinghamshire, England. Immunologic reagents were obtained from Dakopatts, Glostrup, Denmark. SHR and WKY rats were supplied by Madörin/BRL, Frenkendorf, Switzerland.

All cell culture techniques and details of procedures employed for the isolation of vascular smooth muscle cells (VSMC) from rats (SHR and WKY) have been reported before. Cell numbers (growth kinetics) were determined on cell suspensions following enzymatic disaggregation of cell layers and counting in a Coulter (Hialeah, FL) counter. ${ }^{18}$

Plasma-derived serum (PDS) was prepared by the method of Ross and Kariya ${ }^{22}$ and each batch was assessed after sterilization by filtration for its mitogenic potential. Samples ( $10 \%$ final concentration) that stimulated the incorporation of $\left[{ }^{3} \mathrm{H}\right]$-thymidine into DNA to levels greater than $5 \%$ of that obtained using $10 \%$ whole blood serum were rejected; PDS was used in experiments at a final concentration of $1 \%$.

Preparation of extracellular matrix (ECM)-coated plastic culture vessels and dishes, as well as all procedures for S6 kinase activation of quiescent cultures, were described. ${ }^{18}$

The incorporation of $\left[{ }^{3} \mathrm{H}\right]$-thymidine into DNA was measured as described before ${ }^{23}$ and the kinetics of $\left[{ }^{3} \mathrm{H}\right]-$ glycine incorporation into ECM protein was performed as described by ourselves and others. ${ }^{16,19}$ Assays for the activation of ornithine decarboxylase (ODC) were carried out as reported by Hovis et al. ${ }^{24}$

\section{RESULTS}

When quiescent VSMC cultures (SHR and WKY) were exposed to $10 \%$ fetal calf serum (FCS) there was a differential time-dependent activation of a number of important growth associated metabolic events which included S6 kinase, ornithine decarboxylase, DNA synthesis, and $\left[{ }^{3} \mathrm{H}\right]$-thymidine incorporation (Figure 2). The temporal relationship between these events has been well documented ${ }^{25}$ inter alia and the time intervals observed between the induction of, for example S6 kinase and ODC reflect the proliferation rates of the stimulated cultures. SHR-derived cells exhibited shorter time intervals between the induction of S6 kinase and ODC than cells from WKY sources (Figure 2). Although we have shown previously that Ang II differentially stimulated S6 kinase activation in quiescent cultures of VSMC from SHR and WKY sources, ${ }^{26}$ we did not observe any induction of ODC activity or stimulation of $\left[{ }^{3} \mathrm{H}\right]$-thymi- 


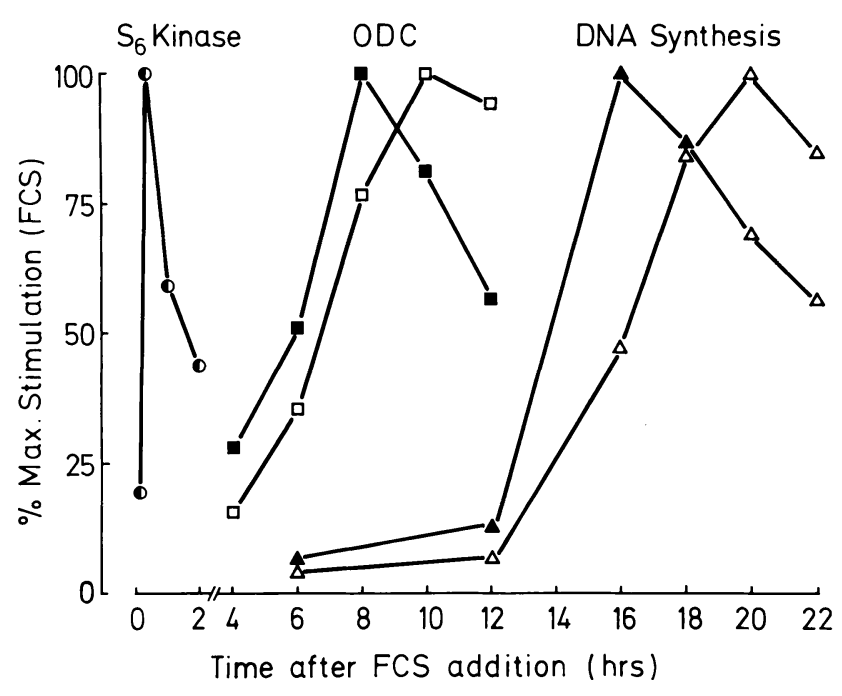

FIGURE 2. Kinetics of activation of important metabolic events leading to cell proliferation in VSMC from SHR and WKY rats. Quiescent cells were exposed to fetal-calf serum (10\%) and the activity of S6 kinase, ODC, and the incorporation levels of [ $\left.{ }^{3} \mathrm{H}\right]-$ thymidine into DNA determined (see Methods). The data represents the mean values from two experiments performed on a pair of SHR and WKY isolates at same passage number and at similar cell densities. Closed symbols represent data from SHR and open symbols, WKY cultures.

dine incorporation by this agonist when added to serum-free medium.

The VSMC from SHR and WKY sources elaborated extracellular matrices during long-term culture in presence of $\mathrm{Na}$ ascorbate, which consisted of a complex blend of connective macro-molecules. ${ }^{27}$ Proliferation rates of WKY cells were differentially stimulated when they were cultured upon matrices elaborated either by themselves or SHR cells in previous passage (Figure 3). Growth rates of SHR cells were not significantly different when they were plated upon matrices elaborated by cells of either type (Figure 3).

When quiescent cultures of VSMC from SHR were exposed to Ang II there was a time-dependent stimulation of incorporation of $\left[{ }^{14} \mathrm{C}\right]$-glycine and $\left[{ }^{3} \mathrm{H}\right]$-glucosamine into extracellular matrix material above levels observed for serum-free medium controls (Figure 4). Similar findings were obtained with cells from normotensive animals (data not shown). The data also suggested a differential stimulation of glycoconjugate synthesis by Ang II since the ratios for the incorporation of the two isotopic matrix precursors were significantly $(P<.05)$ different, $\left(\left[{ }^{3} \mathrm{H}\right] /\left[{ }^{14} \mathrm{C}\right] ; 1.17 \pm 0.2\right.$ for Ang II $v$ $0.77 \pm 0.2$ for controls).

Although under serum-free conditions Ang II was incapable of stimulating mitogenic behavior in VSMC, in the presence of $1 \%$ PDS cells from SHR exhibited an enhanced responsiveness to the agonist leading to a sig-

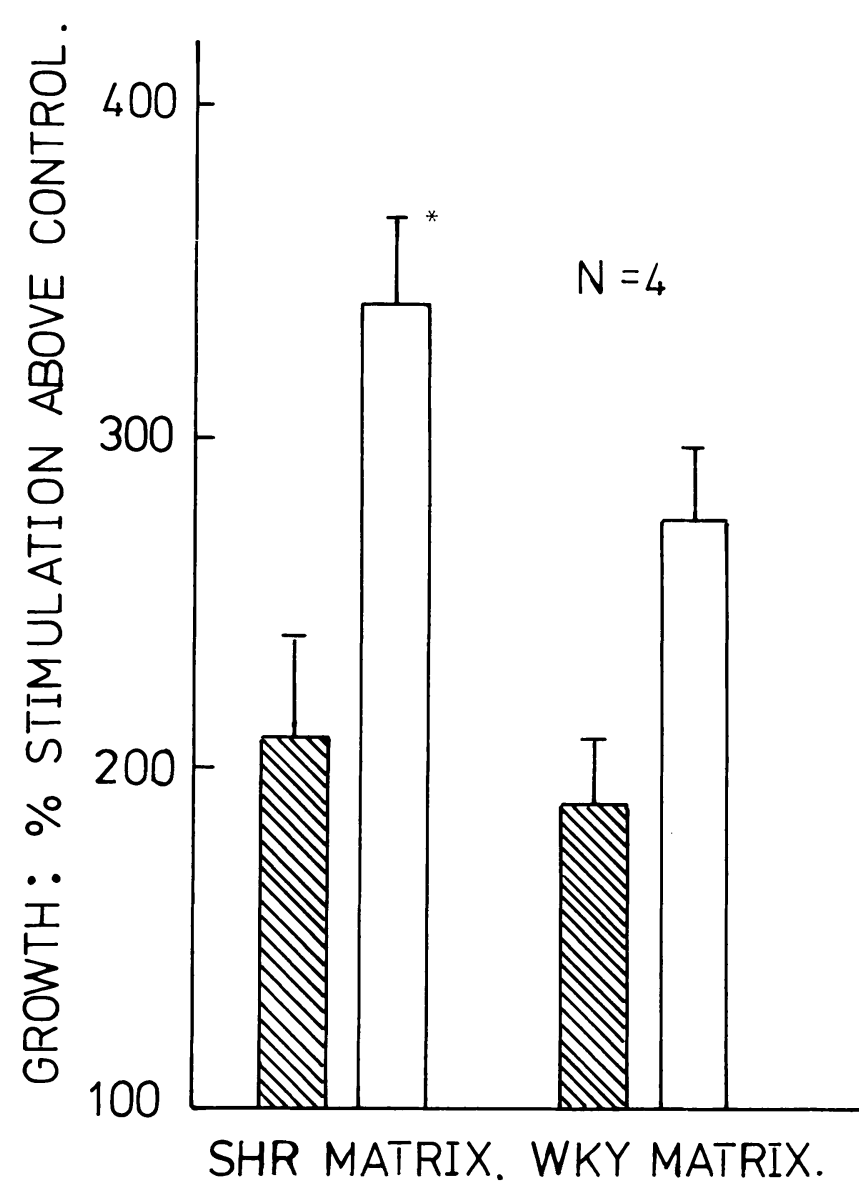

FIGURE 3. Growth stimulation by extracellular matrix substrata. VSMC were plated onto either gelatin-washed or matrixcoated substrata ${ }^{18}$ and grown for 3 days with normal medium. Following the growth period wells were trypsinized and cell numbers determined (see Methods). The data is expressed as the percentage of stimulation in growth (cell number) on the different matrix preparations (from SHR or WKY) relative to growth on gelatinized plastic (100\%) and represents the means $\pm S D$ of repeated $(n=4)$ experiments. The hatched blocks represent data for SHR and *indicates the significance of difference $(\mathrm{P}>.001)$ in cell numbers for WKY when plated upon either SHR-derived ECM or their own.

nificant $(P<.001)$ sustained increase in cell number (Figure 5). We also observed a minimal increase in proliferation rates by cells from WKY rats exposed to Ang II and $1 \%$ PDS, which only reached significance $(P<.01)$ after 9 days in culture.

\section{DISCUSSION}

VSMC from SHR sources exhibit elevated growth rates and enhanced responsiveness to growth stimulants (growth factors, hormones, and FCS) as compared to cells from WKY sources. ${ }^{18,23,28-30}$ We have also reported on the differential stimulation of S6 kinase in the two cell types as a consequence of their exposure to Ang II. ${ }^{26}$ 
FIGURE 4. Kinetics of incorporation of radioactive matrix precursors into ECM macromolecules by VSMC from SHR. Quiescent cultures of SHR smooth muscle cells were exposed to either $\left[{ }^{14} \mathrm{C}\right]$-glycine or $\left[{ }^{3} \mathrm{H}\right]$-glucosamine in the presence or absence of $100 \mathrm{nmol} / \mathrm{L}$ Ang II for the number of times shown. The determination of the levels of incorporation was performed as described under Methods and the data (mean values $\pm S D$ ) is typical of that seen in a number of experiments $(n=4)$. Closed symbols represent cells maintained in the presence of Ang II and open, in its absence.
A

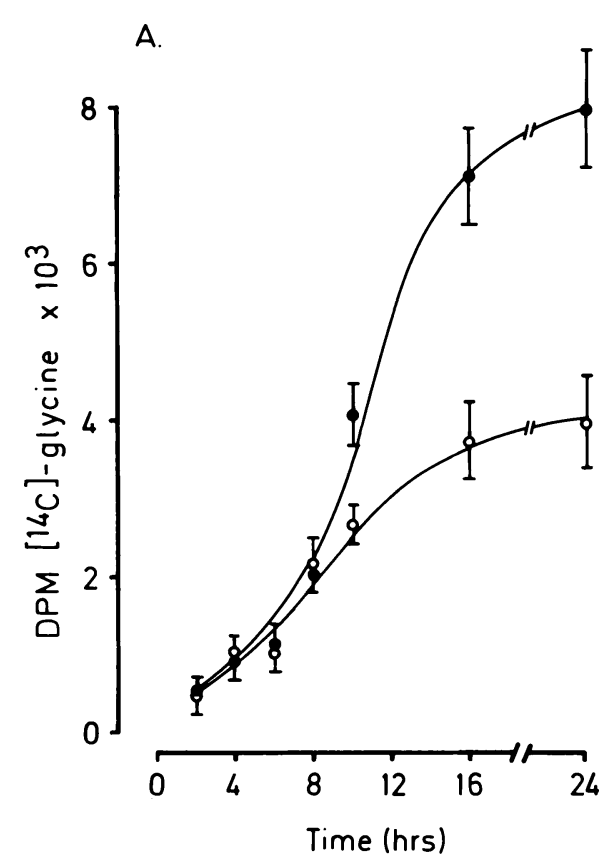

B.

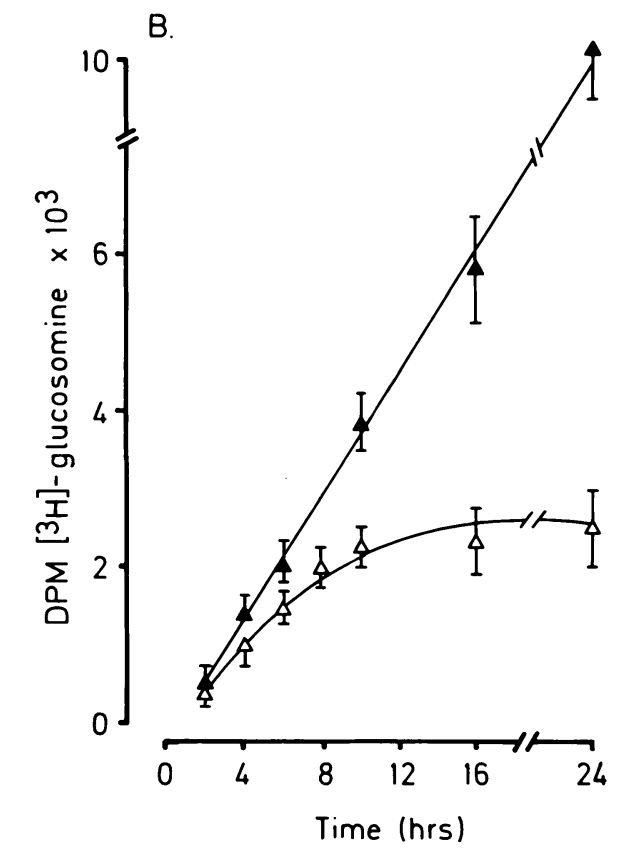

However, this agonist was unable to stimulate the activation of ODC or subsequent events leading to mitosis under serum-free conditions. We have also shown that other potential growth enhancers like low density lipoproteins (LDL) and thrombospondin (TS) behave in a similar manner. ${ }^{20,21}$ FCS, which contains a number of mitogens for VSMC (ie, platelet derived growth factor (PDGF), basic fibroblast growth factor $\left(\mathrm{FGF}_{\mathrm{b}}\right)$, and epidermal growth factor (EGF)) stimulated the induction of all three growth related metabolic events depicted in Figure 2. Cells from SHR responded faster to FCS in terms of ODC activation and $\left[{ }^{3} \mathrm{H}\right]$-thymidine incorporation than did their normotensive (WKY) counterparts; this is a reflection of their faster growth rates in culture.

Ang II stimulation of matrix glycoconjugate synthesis (Figure 4) may contribute to the structural changes that are part and parcel of vascular disease. The extracellular matrix plays an important role in the maintenance of phenotype, ${ }^{10,31,32}$ and our observations that matrix material from SHR stimulated the growth of WKY cells to a greater extent than that elaborated by themselves serves to emphasize the importance of this component of the vessel wall. We have summarized some of the current knowledge and some of our own findings in regard to the interactions of normal vessel wall components (Figure 1). Central to these observations is the evidence that Ang II is capable of stimulating the expression of a number of important compounds which include PDGF A chain, TS, and $\mathrm{TGF}_{\beta} \cdot{ }^{33}$ The induction of PDGF A chain expression in VSMC exposed to Ang II has already been reported $^{11}$ and it may account for our observation of growth stimulation by Ang II of cells from SHR in presence of $1 \%$ PDS (Figure 5). We have found that cell isolates from SHR express and have receptors for $\mathrm{PDGF}_{\mathrm{AA}}$ homodimer, whereas WKY-derived cells only express the growth factor but do not respond to it, since they lack A-type cell surface receptors. ${ }^{34}$ The increase in cell number observed in cultures from hypertensive animals maintained in 1\% PDS medium alone may also be accounted for by their responsiveness to PDGF A-chain homodimer. ${ }^{34}$ The synthesis and secretion of the AA homodimeric form of PDGF by arterial smooth muscle cells has also been observed by others. ${ }^{35}$ The combination of vessel wall components as depicted in the schematic (Figure 1) can realistically lead to the initiation of neointimal formation which typifies vascular pathology in man and experimental animals. We have found that compounds such as TS, LDL, and Ang II are able, in cultured VSMC, of enhancing metabolic events normally associated with proliferation. ${ }^{16,20,21,28,29,36}$ TS alone was not mitogenic to VSMC, but, when administered in combination with EGF, its mitogenic potential was considerably enhanced. ${ }^{8,36}$ Although there is no evidence as yet to suggest the presence of EGF (or its close analogue $\mathrm{TGF}_{\alpha}$ ) in the normal vessel wall, recent data has shown that laminin, which is certainly present, possesses EGF-like sequences within its structure. ${ }^{37}$ It is conceivable that during the course of normal matrix turnover "EGF-like" molecules may arise and that these in combination with TS could behave as a strong mitogenic mixture. Additionally, the stimulation of $\mathrm{TGF}_{\beta}$ expression by cultured smooth muscle cells in response to Ang II exposure ${ }^{33}$ may account for the influence of the vasoactive peptide on matrix synthesis, since $\mathrm{TGF}_{\beta}$ has been shown to not only modulate the growth of smooth muscle cells but also to enhance their synthesis of extra- 


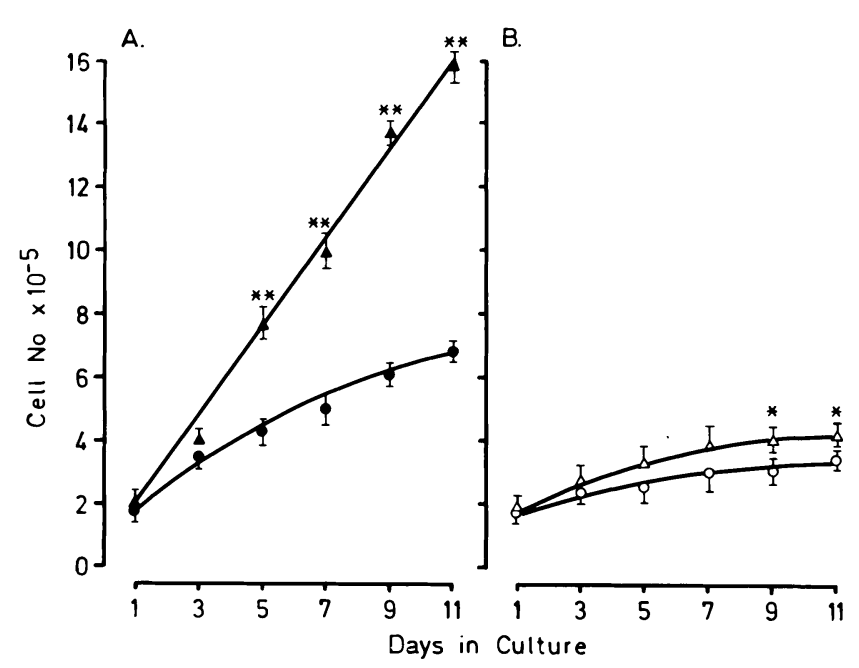

FIGURE 5. Growth kinetics of VSMC from SHR and WKY in presence and absence of Ang II. Cells were plated into 12-well multiwell plates $\left(1.25 \times 10^{5}\right.$ cells $/$ well $)$ in normal medium containing 10\% whole blood serum. After $18 \mathrm{~h}$ medium was replaced with 1\% PDS medium (see Methods) and some wells were further supplemented with Ang II $\left(5 \times 10^{8} \mathrm{~mol} / \mathrm{L}\right)$ on a daily basis. Medium (1\% PDS) was changed every $48 \mathrm{~h}$ and cell numbers determined as described previously. ${ }^{18}$ Experiments $(n=3)$ were performed on cells from (A) SHR and (B) WKY and the data represent the means $\pm S D$. Statistical significance was analyzed using Student's t test for unpaired data and the levels of significance are indicated on the figure as ${ }^{*}, \mathrm{P}<.01 ;{ }^{* *}, \mathrm{P}<.001$.

cellular matrix macromolecules. ${ }^{38}$ In conclusion, it would appear that we no longer have to invoke damage to the endothelium as the stimulus for the changes that lead to neointimal formation since many compounds such as Ang II, alone or in combination with normal constituents of the vessel wall, are potentially capable of pathogenic modulation of medial smooth muscle cells leading to progressive structural hypertrophy, as observed in vascular tissue from hypertensive animals and man.

\section{REFERENCES}

1. Ross R, Glomset JA: The pathogenesis of atherosclerosis. N Engl J Med 1976;295:369-377, 420-425.

2. Baumgartner HR, Haundenschild C: Adhesion of platelets to subendothelium. Ann NY Acad Sci 1972;201:2236.

3. Austin GE, Ratliff NB, Hollman J, et al: J Am Coll Cardiol 1985;6:369-375.

4. Clowes AW, Collazzo RE, Karnovsky MJ: A morphologic and permeability study of luminal smooth muscle cells after arterial injury in the rat. Lab Invest 1978;39:141150.

5. Reidy MA: A reassessment of endothelial injury and arterial lesion formation. Lab Invest 1985;53:513-520.
6. Poole JCF, Florey HW: Changes in the endothelium of the aorta and the behavior of macrophages in experimental atheroma of rabbits. J Pathos Bacteriol 1958;75:245251.

7. Booth RGF, Martin JF, Honey AC, et al: Rapid development of atherosclerotic lesions in the rabbit carotid artery induced by perivascular manipulation. Atherosclerosis 1989;76:257-268.

8. Majack RA, Cook SC, Bornstein P: Control of smooth muscle cell growth by components of the extracellular matrix: Autocrine role for thrombospondin. Proc Natl Acad USA 1986;83:9050-9054.

9. Majack RA, Goodman LV, Dixit VM: Cell surface thrombospondin is functionally essential for smooth muscle cell proliferation. J Cell Biol 1988;106:415-422.

10. Scott-Burden T, Bühler FR: Regulation of smooth muscle proliferative phenotype by heparinoid-matrix interactions. Trends Pharmacol Sci 1988;9:94-98.

11. Naftilan AJ, Pratt RE, Dzau VJ: Induction of plateletderived growth factor A-chain and c-myc gene expression by angiotensin II in cultured rat vascular smooth muscle cells. J Clin Invest 1989;83:1419-1424.

12. Kawahara $Y$, Sunako M, Tsuda $T$, et al: Angiotensin II induces expression of the c-fos gene though protein kinase $\mathrm{C}$ activation and Calcium ion mobilization in cultured vascular smooth muscle cells. Biochem Biophys Res Commun 1988;150:52-59.

13. Bühler FR, Laragh JH, Baer L, et al: Propranolol inhibition of renin secretion. A specific approach to diagnosis and treatment of renin-dependent hypertensive diseases. N Engl J Med 1972;287:1209-1214.

14. Laragh JH: The meaning of plasma renin measurements: renin and sodium-volume-mediated (low renin) form of vasoconstriction in experimental and human hypertension and in the oedematous states of nephrosis and heart failure. J Hypertens 1984;2(suppl 1):141-150.

15. Scott-Burden T, Resink TJ, Baur U, et al: Amiloride sensitive activation of S6 Kinase by angiotensin II in cultured vascular smooth muscle cells. Biochem Biophys Res Commun 1988;151:583-589.

16. Berk BC, Vekstein V, Gordon HM, Tsuda T: Angiotensin II-stimulated protein synthesis in cultured vascular smooth muscle cells. Hypertension 1989;13:305-304.

17. Campbell JH, Campbell GR: in Campbell JH, Campbell GR (eds): Vascular Smooth Muscle in Culture, Vol. 1. Boca Raton, Florida, CRC Press, 1987, pp 15-21.

18. Scott-Burden T, Resink TJ, Baur U, et al: Response to epidermal growth factor by cultured smooth muscle cells from hypertensive rats. Hypertension 1989;13:295304.

19. Jones PA, Scott-Burden T, Gevers W: Glycoprotein elastin and collagen secretion by rat smooth muscle cells. Proc Natl Acad Sci USA 1979;76:353-357.

20. Scott-Burden T, Resink TJ, Baur U, et al: Activation of S6 kinase in cultured vascular smooth muscle cells by submitogenic levels of thrombospondin. Biochem Biophys Res Commun 1988;150:278-286.

21. Scott-Burden T, Resink TJ, Hahn AWA, et al: Induction of growth related metabolism in human vascular smooth muscle cells by low density lipoprotein. J Biol Chem 1989;264:12582-12589. 
22. Ross R, Kariya B: Morphogenesis of vascular smooth muscle in atherosclerosis and cell culture, in Bohr D, Somlyo AP, Sparks HV Jr (eds), Handbook of Physiology, section 2: The Cardiovascular System, Vol. 2. Washington, DC, American Physiological Society, 1980, p. 69.

23. Scott-Burden T, Resink TR, Hahn AWA, Bühler FR: Differential stimulation of growth related metabolism in cultured smooth muscle cells from SHR and WKY rats by combinations of EGF and LDL. Biochem Biophys Res Commun 1989;159:624-632.

24. Hovis JG, Stumpo DJ, Halsey DL, Blackshear PJ: Effects of mitogens on ornithine decarboxylase activity and messenger RNA levels in normal and protein kinase C-deficient NIH-3T3 fibroblasts. J Biol Chem 1986; 261:10380-10386.

25. Chambard J-C, Pouyssegur J: TGF $\beta$ inhibits growth factor-induced DNA synthesis in hamster fibroblasts without affecting the early mitogenic events. J Cell Physiol 1988;135:101 - 107 .

26. Resink TJ, Scott-Burden T, Baur U, et al: Enhanced responsiveness to angiotensin II in vascular smooth muscle cells from spontaneously hypertensive rats is not associated with alterations in protein kinase $\mathrm{C}$. Hypertension $1989 ; 14: 293-303$.

27. Scott-Burden T, Resink TJ, Bürgin M, Bühler FR: Extracellular matrix: differential influence on growth and biosynthesis patterns of vascular smooth muscle cells from SHR and WKY rats. J Cell Physiol 1990;141:267-274.

28. Scott-Burden T, Resink TJ, Bühler FR: Enhanced growth and growth factor responsiveness of vascular smooth muscle cells from hypertensive rats. Cardiovascular Pharmacol 1989;14:S16-S21.

29. Yamori Y, Igawa T, Kanbe T, et al: Mechanism of structural vascular changes in genetic hypertension: analysis on cultured vascular smooth muscle cells from spontaneously hypertensive rats. Clin Sci 1981;61:121s-123s.
30. Haudenschild CC, Grunwald J, Chobanian AV: Effects of hypertension on migration and proliferation of smooth muscle in culture. Hypertension 1985;7:(suppl 1)101-104.

31. Castellot JJ, Wright TC, Karnovsky MJ: Regulation of smooth muscle cell growth by heparin and heparin sulfates. Sem Throm Hem 1987;13:487-503.

32. Herman IM, Castellot JJ: Regulation of smooth muscle cell growth by endothelial-synthesized extracellular matrices. Arteriosclerosis 1987;7:463-469.

33. Hahn AWA, Scott-Burden T, Resink TJ, et al: Angiotensin II induction of PDGF A chain expression in cultured rat vascular smooth muscle cells is preceeded by thrombospondin gene transcription. Eur J Biochem (in press).

34. Resink TJ, Scott-Burden T, Hahn AWA, et al: Specific growth stimulation of cultured smooth muscle cells from spontaneously hypertensive rats by platelet-derived growth factor A chain homodimer. Cell Reg (in press).

35. Sjolund M, Hedin U, Sejersen T, Heldin $\mathrm{CH}$ : Arterial smooth muscle cells express platelet-derived growth factor (PDGF) A chain mRNA, secrete a PDGF-like mitogen and bind exogenous PDGF in a phenotype- and growth state-dependent manner. J Cell Biol 1988;106:403-413.

36. Scott-Burden T, Resink TJ, Bühler FR: Growth regulation in smooth muscle cells from normal and hypertensive rats. J Cardiovasc Pharmacol 1988;12:s124-s127.

37. Panayotou G, End P, Aumailley M, et al: Domains of laminin with growth-factor activity. Cell 1989;56:93101.

38. Penttinen RT, Kobayashi S, Bornstein P: Transforming growth factor $\beta$ increases mRNA for matrix proteins both in the presence and in the absence of changes in mRNA stability. Proc Natl Acad Sci USA 1988;85:1105-1108.

39. Mackie EJ, Halfter W, Liverani D: Induction of tenascin in healing wounds. J Cell Biol 1988;107:2757-2767. 